\title{
Explaining modified 2-min walk test outcomes in male Veterans with traumatic or nontraumatic lower-limb amputation
}

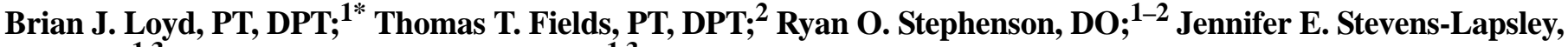 \\ PT, PhD; ${ }^{1,3}$ Cory L. Christiansen, PT, PhD; ${ }^{1,3}$ \\ ${ }^{1}$ Physical Therapy Program, Department of Physical Medicine and Rehabilitation, University of Colorado, Aurora, \\ CO; ${ }^{2}$ Department of Physical Medicine and Rehabilitation and ${ }^{3}$ Geriatric Research Education and Clinical Center, \\ Department of Veterans Affairs Eastern Colorado Health Care System, Denver, CO
}

\begin{abstract}
Little evidence exists to support the presence of differences in spatiotemporal gait parameters and ambulation ability between those individuals with traumatic and nontraumatic lower-limb amputation (LLA). We conducted an exploratory study of 81 male Veterans with unilateral amputation to quantify differences in spatiotemporal gait parameters and ambulatory mobility between Veterans with traumatic and nontraumatic LLA. Furthermore, we identified variables that significantly contributed to the explanation of variability in modified 2-min walk test distance. All participants completed the modified 2-min walk test and a spatiotemporal gait analysis using an instrumented walkway during a routine physical therapy visit. Veterans with nontraumatic LLA walked significantly shorter mean distances during a modified 2-min walk test than Veterans with traumatic LLA. Variables identified as significant contributors to modified 2-min walk test variability were amputated limb stance time, amputated limb step length, and percentage of the gait cycle spent in double support. These findings demonstrate that differences in spatiotemporal gait parameters and ambulatory mobility exist between Veterans with traumatic and nontraumatic LLA and identify important spatiotemporal parameters of gait contributing to this decline. These parameters should be considered as targets for intervention and future investigation.
\end{abstract}

Key words: 2-min walk test, ambulatory mobility, amputation, gait, lower-limb amputation, nontraumatic, spatiotemporal gait parameters, traumatic, unilateral amputation, Veterans.

\section{INTRODUCTION}

Ambulatory mobility following lower-limb amputation (LLA) is a complex process with significant implications for patient physical function and quality of life. Ambulatory mobility is one of the single greatest predictors of quality of life in people with LLA [1] and is associated with improved social function [2]. Many factors contribute to ambulatory mobility after LLA, including preoperative function; presence of comorbidities; and modifiable factors related to rehabilitation, such as prosthetic fit/function and spatiotemporal parameters of movement [3]. Past research has focused on optimizing

Abbreviations: \%GC = percent of gait cycle, $2 \mathrm{MWT}=2$-min walk test, $\mathrm{BMI}=$ body mass index, $\mathrm{BOS}=$ base of support, FCI = Functional Comorbidity Index, ICC = intraclass correlation coefficients, LLA = lower-limb amputation, $\mathrm{NIH}=$ National Institutes of Health, SD = standard deviation, SF-36 = 36-Item Short Form Health Survey, TFA = transfemoral amputation, TTA = transtibial amputation, VA = Department of Veterans Affairs.

*Address all correspondence to Brian Loyd, PT, DPT; Gersten Education and Research Office Bldg, 500 RM EG 308, 13001 E 17th Pl, Aurora, CO 80045; 303-724-9590; fax: 303-724-2444.

Email: brian.loyd@ucdenver.edu

http://dx.doi.org/10.1682/JRRD.2015.03.0038 
prosthetic fit/function [4-5], but evidence is needed to demonstrate the association between modifiable spatiotemporal gait deficits and ambulatory mobility after LLA.

Following LLA, gait deficits often include shorter ipsilateral or contralateral step length, increased double limb support time, wider base of support (BOS), and decreased step rate (cadence). Deficits in these spatiotemporal parameters are associated with decreased walking speed and endurance [6], both of which are typically captured when assessing a patient's ambulatory mobility with tests such as the 2-min walk test (2MWT), a clinical measure of ambulatory mobility shown to have good validity for use in medically complex patients, including those with LLA [6-8]. Furthermore, each of these spatiotemporal parameters has been suggested as a potential rehabilitation target to improve ambulatory mobility after LLA in patients with both transtibial amputation (TTA) and transfemoral amputation (TFA) [9-10]. Preliminary evidence has shown that gait parameters, including step length and stance time, can demonstrate increased between-limb symmetry with specified step training in patients following unilateral TTA [11]. However, the ideal amount of between-limb spatiotemporal symmetry is not known; the loss of a joint (or joints) with amputation creates some level of chronic asymmetry [12]. Although debate exists about the optimum rehabilitation goals, it is widely accepted that an excessive level of gait pattern change is associated with the development of dysfunction [13]. For example, excessive asymmetrical movement and loading of the lower limbs predisposes patients to a sequela of health conditions, including osteoarthritis and back pain [14].

In addition to spatiotemporal gait alterations after LLA, ambulatory mobility also depends on patient demographics, health status, and amputation characteristics, which vary greatly in the heterogeneous LLA population. Past studies have found that increased age, a complex comorbidity status, level of amputation, time since amputation, and body mass index (BMI) all have a significant influence on ambulatory mobility following LLA [15-17]. However, the individual and combined influence of each of these factors on ambulation are not well defined [18]. It remains unclear how demographics, health status, amputation characteristics, and spatiotemporal gait deficits affect ambulatory mobility, particularly relative to one another.

Heterogeneity in the LLA population is also characterized by reason for amputation (traumatic or nontraumatic). Both forms of amputation are characterized by unique presentations, including age and health status.
Patients who have undergone nontraumatic LLA resulting from, for example, infection and dysvascularization are more likely to be affected by a common group of comorbid health conditions, including diabetes and renal disease. In contrast, patients who have undergone traumatic LLA do not exhibit any one or group of health conditions $[14,18]$. In fact, more than 50 percent of traumatic LLA occurred in Veterans under the age of $65 \mathrm{yr}$ and only 4.4 percent of Veterans with traumatic LLA had complications of renal disease, compared to nearly 10 percent of Veterans with nontraumatic LLA [19]. By describing the relationship between demographic/health-related factors, amputation characteristics, and spatiotemporal gait deficits across groups of Veterans with either traumatic or nontraumatic LLA, we hope to identify modifiable risk factors that contribute to a patient's functional gait ability.

Therefore, this study was designed with two primary purposes: (1) quantify the differences in spatiotemporal gait measures, walking speed, and modified 2MWT distances between groups of Veterans with traumatic and nontraumatic LLA and (2) identify the explanatory variables that contribute to ambulatory mobility, as measured by the modified 2MWT, using candidate variables from the domains of spatiotemporal gait parameters, demographics, health status, and amputation characteristics. We hypothesized that (1) Veterans with nontraumatic LLA would have greater deficits in spatiotemporal measures of gait, slower walking speeds, and shorter modified 2MWT distances than Veterans with traumatic LLA; (2) variables from each of the three domains would contribute in different ways to the explanation of variability in modified 2MWT distance; and (3) depending on the cause of amputation (traumatic vs nontraumatic), variables from the three domains would contribute in different ways to $2 \mathrm{MWT}$ distances.

\section{METHODS}

\section{Patients}

Participant data were collected from a retrospective chart review and a database of Veterans who received physical rehabilitation at the Department of Veterans Affairs (VA) Regional Amputation Center in Denver, Colorado, between September, 2012, and July, 2014. The study included 81 Veterans who had undergone major unilateral LLA and were independent community ambulators (using assistive devices if needed) participating in routine 
follow-up at the VA outpatient clinic. Veterans must have completed a minimum of three trials of overground walking, collected during a single routine clinical visit on the GAITRite Electronic Walkway system (version 3.9, CIR Systems Inc; Franklin, New Jersey). All testing was completed by one of two licensed physical therapists as part of routine clinical practice. Demographic information, amputation characteristics, and health-related data for each Veteran were acquired through medical record review. These data were recorded nearest the date that each Veteran's GAITRite data were collected.

\section{Outcomes}

We chose the 2MWT as the primary measure of ambulatory mobility because it provides information regarding both walking speed and endurance not captured with a measure of walking speed alone. The 2MWT has been found to function as a powerful surrogate measure of a patient's ambulatory mobility, primarily in medically complex patients, including those with LLA [7-8]. The 2MWT has also been shown to correlate strongly with the 6-min walk test and has been deemed more appropriate for patients with severe disabilities [20]. Furthermore, the 2MWT is useful in assessing walking limitations, prosthetic use, and functional mobility following LLA [7-8]. Courses previously used for performing the 2MWT range from the $50 \mathrm{ft}$ shuttle course, recommended in the National Institutes of Health $(\mathrm{NIH})$ Toolbox Motor Battery, to courses using a $122 \mathrm{~m}$ rectangular hallway [21-22]. Though the course used for the 2MWT has been shown to vary greatly among studies, we will refer to the test used in this study as a modified $2 M W T$ to distinguish it from the NIH recommended method. Our modified 2MWT required that Veterans walk along a $450 \mathrm{ft}$ rectangular hallway course in the clinic for $2 \mathrm{~min}$. Veterans were instructed to "cover as much distance as you can in 2 min without running; you are allowed to use your assistive device and take breaks as needed, but the timer will continue to run.” The total distance walked was recorded for each participant.

\section{Explanatory Measures}

\section{Spatiotemporal Gait Measures}

Spatiotemporal parameters of gait were collected using the GAITRite system. The system records data using 16,128 pressure sensors built into a $61 \mathrm{~cm}$ by $427 \mathrm{~cm}$ mat. As Veterans walk over the mat, the pressure sensors identify the location and the activation and deac- tivation times of each footfall. Data collection sessions consisted of three trials of level walking, beginning $10 \mathrm{ft}$ beyond the mat to allow for acceleration. Veterans were instructed to "walk slightly faster than normal, like you are trying to cross a street before the light changes, and continue walking beyond the length of the mat.” Veterans were allowed to use assistive devices as needed. All recorded footfall data were exported using GAITRite software. All GAITRite testing was performed immediately before performing modified 2MWT testing. Mean values for gait parameters of interest (step length, single limb stance time, BOS, double limb support time, gait speed, and step rate) were calculated using the average of the three trials. These gait variables were chosen for analysis because they have been linked to deviations identified with gait after LLA $[18,23]$ and general physical function and health status [24-25].

The GAITRite system has been validated through studies comparing it to other spatiotemporal gait measurement systems. When compared to an eight-camera motion capture system, the GAITRite system was found to have excellent concurrent validity for spatiotemporal gait variables, demonstrating a mean difference of 1.5 percent or less for parameter calculations of step length, stride length, single support time, and velocity [26]. The GAITRite system has also been found to correlate strongly with the Clinical Stride Analyzer (B \& L Engineering; Santa Ana, California), a widely used spatiotemporal gait measure that uses insole pressure sensors. Intraclass correlation coefficients (ICC) for gait speed, stride length, and step rate were ICC $(2,1)=0.99$, and single limb support times demonstrated moderate to high correlations: ICC $(2,1)=0.61-0.91$ [27].

Between-limb symmetry ratios were calculated by using mean values for step length and stance time as follows: absolute symmetry ratio = larger value / smaller value. Temporal and spatial ratios provide information regarding the magnitude of asymmetry present. Based on scientific evidence that supports greater step lengths and shorter stance times in the amputated lower limb, a ratio of 1.0 indicates perfect symmetry; a score $<1.0$ indicates asymmetry, with smaller values indicating greater asymmetry.

\section{Electronic Medical Record}

Demographic, anthropometric, and health-related information was collected from the VA electronic medical record system. Veteran comorbidity information was recorded using the Functional Comorbidity Index (FCI), an 18-item 
index consisting of diagnoses that have been shown to contribute to functional decline [28]. Items are scored by a simple counting of yes/no responses. We chose the FCI for this study because of its ease of clinical use and strong correlation with the 36-Item Short Form Health Survey (SF36), a commonly cited measure of patient-reported physical function [29]. Furthermore, the FCI includes information about the presence of modifiable comorbidities (e.g., peripheral vascular disease, high blood pressure) in each patient; therefore, the relation of the FCI to modified 2MWT distance provides important rehabilitation information. Other data collected from the medical record included sex, age, BMI, and use of assistive device. Amputation characteristics consisted of laterality of the amputated limb, level of amputation, reason for amputation, and time since amputation.

\section{Statistical Analysis}

Descriptive statistics were calculated for the entire sample and were also described for groups based on traumatic and nontraumatic LLA. Means and standard deviations were calculated for continuous variables, and frequency counts were used for categorical variables. To determine differences between traumatic and nontraumatic LLA groups in spatiotemporal gait parameters, walking speed, and modified 2MWT distance, we performed independent $t$-tests.

To analyze our second objective, identifying which variables help explain variability in modified 2MWT distance, we categorized variables into three domains: spatiotemporal gait parameters, demographics/health-related factors, and amputation characteristics (Table 1). A twostep process was then performed to test for variable inclusion. We first tested each variable for correlation with the modified 2MWT distance using univariate regression models. Those variables found to be significant contributors to modified 2MWT distance $(p<0.05)$ in the univariate model were then tested for collinearity using bivariate models of each combination of significant variables within a domain. Variables that no longer contributed $(p>0.1)$ to modified 2MWT distance in the presence of variables from the same domain were excluded from the regression analysis. Using a stepwise forward procedure, the dependent variable, modified 2MWT distance, was regressed against the model of best fit from the included variables. This process involves testing the fit of the model with the addition of each variable, added in individual steps. Variables that met a model comparison criterion $(p<0.05)$ and contributed to model fit (increased adjusted $R^{2}$ ) were added, beginning with the most significant. This process
Table 1.

Domains of explanatory variables used in regression analysis for 2-min walk test distance.

\begin{tabular}{ll}
\hline \multicolumn{1}{c}{ Domain } & \multicolumn{1}{c}{ Variable } \\
\hline Spatiotemporal Gait Parameters & Step length asymmetry \\
& Single leg stance time asymmetry \\
& Double support (\%GC) \\
& Amputated limb stance time \\
& Nonamputated limb stance time \\
& Amputated limb step length \\
& Nonamputated limb step length \\
& Base of support \\
& Step rate \\
Demographic and Health Related & Body mass index \\
& Functional Comorbidity Index \\
& score (comorbidity index total) \\
Amputation Characteristics & Age \\
& Years since amputation \\
\hline \%GC = percent of gait cycle. & Level of amputation \\
\hline
\end{tabular}

was repeated until all variables meeting the fit criterion were included.

As a final exploratory step, we examined differing contributions of the model for the groups of Veterans with traumatic and nontraumatic LLA by regressing modified 2MWT distance on the final model from the forward regression to both groups individually. Model fit between the two groups was compared using adjusted $R^{2}$. All analyses was performed using statistical analysis software (SAS Institute Inc; Cary, North Carolina).

\section{RESULTS}

\section{Participants}

Data were collected from the database on 81 male individuals; 49 had traumatic amputation and 32 had nontraumatic amputation. The data set comprised 58 Veterans who had undergone a unilateral TTA (33 traumatic, 25 nontraumatic) and 23 who had undergone a unilateral TFA (16 traumatic, 7 nontraumatic). The group had a mean ( \pm standard deviation [SD]) age of $57.8( \pm 13.8)$ yr, BMI of $28.1( \pm 4.8)$, comorbidity index score of 3.2 $( \pm 1.9)$, and time since amputation of $19.5( \pm 22.6)$ yr. Group characteristics separated by nontraumatic and traumatic LLA groups are presented in Table 2. 
Table 2.

Demographic characteristics and gait parameters between Veterans with traumatic and nontraumatic lower-limb amputation (LLA).

\begin{tabular}{|c|c|c|c|}
\hline Variable & $\begin{array}{c}\text { Nontraumatic LLA }(n=32), \\
\text { mean } \pm \text { SD }\end{array}$ & $\begin{array}{c}\text { Traumatic LLA }(n=49) \\
\text { mean } \pm \text { SD }\end{array}$ & $p$-Value \\
\hline 2-Min Walk Test Distance (m) & $129.46 \pm 35.71$ & $146.12 \pm 35.61$ & $0.04^{*}$ \\
\hline Walking Speed (m/s) & $1.19 \pm 0.36$ & $1.28 \pm 0.31$ & 0.27 \\
\hline Absolute Step Length Symmetry Ratio & $0.89 \pm 0.08$ & $0.93 \pm 0.06$ & $0.04^{*}$ \\
\hline Absolute Stance Time Symmetry Ratio & $0.93 \pm 0.05$ & $0.93 \pm 0.04$ & 0.54 \\
\hline Amputated Limb Step Length (m) & $0.38 \pm 0.07$ & $0.40 \pm 0.06$ & 0.15 \\
\hline Nonamputated Limb Step Length (m) & $0.37 \pm 0.07$ & $0.39 \pm 0.06$ & 0.28 \\
\hline Amputated Limb Stance Time (s) & $0.61 \pm 0.09$ & $0.58 \pm 0.08$ & 0.21 \\
\hline Nonamputated Limb Stance Time (s) & $0.57 \pm 0.07$ & $0.55 \pm 0.07$ & 0.29 \\
\hline Double Support (\%GC) & $29.00 \pm 5.10$ & $27.10 \pm 4.40$ & 0.08 \\
\hline Base of Support (cm) & $15.90 \pm 4.35$ & $15.00 \pm 5.22$ & 0.41 \\
\hline Step Rate (steps/min) & $102.00 \pm 22.06$ & $107.80 \pm 12.00$ & 0.18 \\
\hline Age (yr) & $60.30 \pm 11.41$ & $56.10 \pm 15.07$ & 0.17 \\
\hline Time Since Amputation (yr) & $5.20 \pm 8.12$ & $25.80 \pm 18.94$ & $<0.001^{*}$ \\
\hline Comorbidity Index Total & $3.90 \pm 1.92$ & $2.70 \pm 2.64$ & $0.004^{*}$ \\
\hline Body Mass Index $\left(\mathrm{kg} / \mathrm{m}^{2}\right)$ & $28.40 \pm 5.67$ & $27.90 \pm 4.11$ & 0.68 \\
\hline \multicolumn{4}{|l|}{$\begin{array}{l}\text { Note: Amputation level chi-square }=0.32 . \\
\text { \% Significant at } p<0.05 . \\
\% G C=\text { percent of gait cycle, } \mathrm{SD}=\text { standard deviation. }\end{array}$} \\
\hline
\end{tabular}

\section{Group Differences: Nontraumatic versus Traumatic Lower-Limb Amputation}

We found significant differences between the traumatic and nontraumatic LLA groups for step length symmetry ratio (0.93 vs 0.89 , respectively; $p=0.04$ ) and 2MWT distance (146.12 m vs $129.46 \mathrm{~m}$, respectively; $p=0.04)$. The two groups also significantly differed in time since amputation (25.8 yr vs $5.2 \mathrm{yr}$, respectively; $p<$ $0.001)$ and comorbidity index total score (2.7 vs 3.9, respectively; $p=0.004$ ) (Table 2 ).

\section{Regression Models}

Nine variables met inclusion for the forward stepwise regression procedure: age, FCI total score, amputated limb stance time, nonamputated limb stance time, amputated limb step length, nonamputated limb step length, BOS, double limb support time, and step rate. Completion of the forward regression procedure produced a final model comprising three variables: amputated limb stance time, amputated limb step length, and double support. This model explained 56 percent (adjusted $R^{2}=0.56$ ) of the variation in modified 2MWT distance. In our sample, we found that an increase in amputated limb step length by $1 \mathrm{~cm}$ leads to a mean increase in modified 2MWT distance of $2.1 \mathrm{~m}$. Amputated limb stance time affected mod- ified 2MWT distance in a similar but opposite fashion: an increase in stance time results in decreased mean distance walked. Increases in double limb support time (\% of gait cycle [\%GC]) also resulted in reduced modified 2MWT distances (Table 3).

When this model was fit in subgroups of amputation type, it was found to explain 39 percent (adjusted $R^{2}=$ 0.39 ) of the variation in modified 2MWT for those with traumatic amputation and 73 percent (adjusted $R^{2}=0.73$ ) of the variation in modified 2MWT for those with nontraumatic LLA. These two models also demonstrated the same increases and decreases in modified 2MWT for changes in each of the three variables.

\section{DISCUSSION}

The purpose of this study was twofold. The first aim was to quantify differences in demographic and healthrelated variables, spatiotemporal gait parameters, walking speed, and modified 2MWT distance between Veterans with traumatic LLA and nontraumatic LLA. We hypothesized that those Veterans with nontraumatic LLA would demonstrate higher levels of comorbidities, greater deficits in spatiotemporal gait parameters, slower walking speed, 
Table 3.

Regression model used for explanation of 2-min walk test distance. Beta coefficients representing the change in meters for every one unit change in the measure, $p$-values, and adjusted $R^{2}$ for the model.

\begin{tabular}{ccc}
\hline \multicolumn{1}{c}{ Variable } & Coefficient \pm SD & $\boldsymbol{p}$-Value \\
\hline Entire Sample $(N=81)^{*}$ & $<0.001^{\dagger}$ \\
Amputated Limb Step Length (cm) & $2.10 \pm 0.61(\mathrm{~m})$ & $0.001^{\dagger}$ \\
Amputated Limb Stance Time (s) & $-1.20 \pm 0.39(\mathrm{~m})$ & $0.003^{\dagger}$ \\
Double Support Time (s) & $-0.02 \pm 0.08(\mathrm{~m})$ & $0.04^{\dagger}$ \\
Traumatic Amputation $(n=49)^{\ddagger}$ & & $<0.001^{\dagger}$ \\
Amputated Limb Step Length (cm) & $2.21 \pm 0.90(\mathrm{~m})$ & $0.02^{\dagger}$ \\
Amputated Limb Stance Time (s) & $-0.49 \pm 0.71(\mathrm{~m})$ & 0.48 \\
Double Support Time (s) & $-0.02 \pm 0.01(\mathrm{~m})$ & 0.10 \\
Nontraumatic Amputation ( $n=32)^{\S}$ & & $<0.001^{\dagger}$ \\
Amputated Limb Step Length (cm) & $2.41 \pm 0.87(\mathrm{~m})$ & $0.01^{\dagger}$ \\
Amputated Limb Stance Time (s) & $-1.66 \pm 0.40(\mathrm{~m})$ & $<0.001^{\dagger}$ \\
Double Support Time (s) & $-0.01 \pm 0.01(\mathrm{~m})$ & 0.39 \\
\hline
\end{tabular}

${ }^{*}$ Adjusted $R^{2}=0.56$.

${ }^{\dagger}$ Significant at $p<0.05$.

${ }^{\ddagger}$ Adjusted $R^{2}=0.39$.

$\S_{\text {Adjusted }} R^{2}=0.73$.

$\mathrm{SD}=$ standard deviation

and shorter modified 2MWT distance compared with those with traumatic amputation. In the group with nontraumatic LLA, we saw significantly worse step length symmetry, higher FCI scores, and shorter modified 2MWT distances.

The sample of Veterans with LLA used in this study performed similarly on the 2MWT to those Veterans who participated in a study by Gremeaux et al., which examined a sample of 64 Veterans with mean LLA age $( \pm S D)$ $58( \pm 16)$ yr who walked a distance of $103( \pm 50) \mathrm{m}$ [8]. The distances walked by Veterans with LLA are substantially shorter than expected for nondisabled individuals. For example, a cohort of 417 nondisabled male individuals of mean age ( \pm SD) $49.7( \pm 18.6)$ yr walked a mean distance $( \pm \mathrm{SD})$ of $189.4( \pm 35.5) \mathrm{m}$ during the 2MWT [30]. In addition, 2MWT distances are correlated with poorer scores on the function subscore of the SF-36 across a range of Veterans with LLA [7]. Our results also show that Veterans with nontraumatic LLA have relatively shorter 2MWT distances than those with traumatic LLA. These findings support past evidence that nontraumatic LLA may result in lower physical activity levels and decreased functional ability, secondary to a complex health status [31-32]. To examine the underlying mechanisms for differences in 2MWT distances between Veterans with traumatic and nontraumatic LLA, it is important to examine the spatio- temporal gait parameters that may result in differing levels of functional mobility.

Past studies have demonstrated group differences between Veterans with traumatic and nontraumatic LLA for certain spatiotemporal parameters, including step rate and single limb stance time, as well as differences in metabolic cost of walking [3,33-34]. One particular study, completed by Barth et al., found that patients with dysvascular amputation spent shorter amounts of time on the amputated limb than the sound limb and had a lower step rate compared with patients with traumatic LLA [33]. Our results also demonstrated differences in spatiotemporal parameters between the two groups, including a significant difference in step length symmetry between Veterans with nontraumatic LLA (0.89) and Veterans with traumatic LLA (0.93). These differences reported in step length and stance time are of clinical significance; they may be attributed to poor balance or decreased contralateral pushoff, both of which can limit walking function [35-36]. By quantifying group differences in spatiotemporal gait parameters and ambulatory mobility, our findings are some of the first to provide direct comparison between Veterans with traumatic and nontraumatic LLA. These findings contribute to the body of literature by indicating that greater deficits in walking ability may be expected in Veterans with nontraumatic LLA and should be studied further.

The second aim of this study was to examine variables that might contribute to differences in modified 2MWT distance. We hypothesized that, divided into domains of demographic and health-related variables, amputation characteristics, and spatiotemporal gait parameters, variables from each domain would influence function following LLA [37]. Surprisingly, only amputated limb stance time, amputated limb step length, and double support time were found to significantly contribute to modified 2MWT distance. These three variables accounted for nearly 60 percent of the variation seen in modified 2MWT distance. A similar study by Sansam et al. identified a relationship between single limb stance time on the amputated limb and scores on the Timed "Up and Go" test [5]. This finding demonstrates that static measures of amputated limb single limb balance and dynamic measures of single limb stance time during gait, shown in our results, play an important role in functional walking ability. In fact, these changes, particularly in the amputated limb, are of clinical relevanceproviding the rehabilitation clinician with modifiable targets for intervention, which may improve global walking ability. Darter et al. found that patients following LLA 
demonstrate improved spatiotemporal gait parameters, primarily step length, following step training; findings from that study bolster our findings by demonstrating the effects of training on gait variables we have identified to influence gait function [11]. As an exploratory analysis, we examined whether amputated single limb support time, amputated limb step length, and double support (\%GC) would explain different levels of variability in modified 2MWT distance in subgroups with traumatic and nontraumatic LLA. Our findings demonstrated that these three variables account for nearly 75 percent of the variability in Veterans with nontraumatic LLA, and they explain a substantially smaller amount of variability (39\%) for those Veterans with traumatic LLA. This finding supports our hypothesis that the two subgroups of Veterans with LLA would present differently. The influence of these variables on walking function could explain, in part, why past studies have found that patients with nontraumatic LLA demonstrate lower levels of daily walking and physical activity [36,38-39]. Therefore, these findings provide important evidence for future investigations as well as information the rehabilitation clinician can use to prioritize treatment targets for Veterans within each group. For example, Veterans with nontraumatic LLA may require more focused intervention to address amputated limb stance time than a Veteran with a traumatic LLA.

The use of retrospectively collected, cross-sectional data limited our ability to examine other important patient characteristics that may alter ambulatory mobility, including patient activity level, prosthesis use, prosthesis type, rehabilitation status, and surgical procedure. Although our findings provide important insight into differences between Veterans with traumatic and nontraumatic LLA, we were surprised not to find similar group differences in other spatiotemporal variables and walking speed, a result that may be attributable to sample size. Furthermore, retrospective data collection did not allow for altering the course used during the modified 2MWT. The variability in 2MWT courses limits the ability to compare results between our study and others [7,21-22,30,40]. The 2MWT course used in our study differed from the NIH recommended course [22]. However, we can make important conclusions about patient function, even in the presence of variations of the 2MWT course [21]. It is also important to note the difference in time since amputation between the two groups in our study. Even though time since amputation was not a significant contributor to the model explaining modified 2MWT performance, we did find a significantly shorter time (mean \pm SD) since amputation for those with nontraumatic LLA than those with traumatic LLA (5.2 [ \pm 8.12$]$ yr vs $25.8[ \pm 18.94]$ yr, respectively; $p<0.001$ ). Therefore, when examining walking performance between Veterans with traumatic and nontraumatic LLA, the potential for time since amputation to influence group differences must still be considered. Also, only male Veterans participated in this study, which might limit its generalizability to other populations of patients with LLA.

\section{CONCLUSIONS}

Differences found between the two groups in modified 2MWT distances demonstrate that functional gait ability varies between patients with traumatic and nontraumatic LLA. These findings also demonstrate that those Veterans with nontraumatic LLA may have greater deviations in step length. Differences between the two groups provide important preliminary evidence for clinical intervention and future study. Furthermore, the findings of our regression model indicate that modifiable parameters of gait, such as amputation limb stance time, step length, and double support (\%GC) play a significant role in ambulatory mobility and account for more variability than age, spatiotemporal symmetry, or healthrelated conditions. These three variables provide clinicians with important targets for assessment that, if present, can significantly improve patient function through intervention. The effect of these gait parameters on 2MWT distance indicate that deviations from "normal" in these measures can influence ambulatory mobility. Though some deviation from "normal" is expected with the loss of a limb, future studies are warranted to determine the level of deviation that is considered acceptable when weighing the effect that each of these deviations was found to have on ambulatory mobility.

\section{ACKNOWLEDGMENTS}

\section{Author Contributions:}

Study concept and design: B. J. Loyd, C. L. Christiansen. Acquisition of data: B. J. Loyd, T. T. Fields.

Analysis and interpretation of data: B. J. Loyd, C. L. Christiansen. Drafting of manuscript: B. J. Loyd, C. L. Christiansen, J. E. StevensLapsley.

Critical revision of manuscript for important intellectual content: J. E. Stevens-Lapsley, T. T. Fields, R. O. Stephenson. 
Statistical analysis: B. J. Loyd.

Study supervision: B. J. Loyd, C. L. Christiansen, J. E. Stevens-Lapsley.

Financial Disclosures: The authors have declared that no competing financial interests exist.

Funding/Support: This material was based on work supported by the NIH (grant K12-HD05593).

Additional Contributions: We would like to acknowledge Maria Larson, SPT; Mariah Shultz, SPT; and Spring Mayer, PT, DPT for assistance with collecting data.

Institutional Review: All study procedures were approved by the Colorado Multiple Institution Review Board \#12-0993 and VA Eastern Colorado Investigative Review Board \#12-0993.

Participant Follow-Up: The authors have no plans to notify study subjects of the publication of this article because of lack of contact information.

\section{REFERENCES}

1. Pell JP, Donnan PT, Fowkes FG, Ruckley CV. Quality of life following lower limb amputation for peripheral arterial disease. Eur J Vasc Surg. 1993;7(4):448-51.

[PMID:8359304] http://dx.doi.org/10.1016/S0950-821X(05)80265-8

2. Fortington LV, Dijkstra PU, Bosmans JC, Post WJ, Geertzen JH. Change in health-related quality of life in the first 18 months after lower limb amputation: A prospective, longitudinal study. J Rehabil Med. 2013;45(6):587-94. [PMID:23624575] http://dx.doi.org/10.2340/16501977-1146

3. van Velzen JM, van Bennekom CA, Polomski W, Slootman JR, van der Woude LH, Houdijk H. Physical capacity and walking ability after lower limb amputation: A systematic review. Clin Rehabil. 2006;20(11):999-1016.

[PMID:17065543] http://dx.doi.org/10.1177/0269215506070700

4. Kahle JT, Highsmith MJ, Hubbard SL. Comparison of nonmicroprocessor knee mechanism versus C-Leg on Prosthesis Evaluation Questionnaire, stumbles, falls, walking tests, stair descent, and knee preference. J Rehabil Res Dev. 2008;45(1):1-14. [PMID:18566922] http://dx.doi.org/10.1682/JRRD.2007.04.0054

5. Sansam K, O’Connor RJ, Neumann V, Bhakta B. Clinicians' perspectives on decision making in lower limb amputee rehabilitation. J Rehabil Med. 2014;46(5):447-53. [PMID:24590358]

http://dx.doi.org/10.2340/16501977-1791

6. Genin JJ, Bastien GJ, Franck B, Detrembleur C, Willems PA. Effect of speed on the energy cost of walking in unilateral traumatic lower limb amputees. Eur J Appl Physiol. 2008;103(6):655-63. [PMID:18478251] http://dx.doi.org/10.1007/s00421-008-0764-0
7. Brooks D, Parsons J, Hunter JP, Devlin M, Walker J. The 2minute walk test as a measure of functional improvement in persons with lower limb amputation. Arch Phys Med Rehabil. 2001;82(10):1478-83. [PMID:11588757] http://dx.doi.org/10.1053/apmr.2001.25153

8. Gremeaux V, Damak S, Troisgros O, Feki A, Laroche D, Perennou D, Benaim C, Casillas JM. Selecting a test for the clinical assessment of balance and walking capacity at the definitive fitting state after unilateral amputation: A comparative study. Prosthet Orthot Int. 2012;36(4):415-22. [PMID:22389424] http://dx.doi.org/10.1177/0309364612437904

9. Sagawa Y Jr, Turcot K, Armand S, Thevenon A, Vuillerme $\mathrm{N}$, Watelain E. Biomechanics and physiological parameters during gait in lower-limb amputees: A systematic review. Gait Posture. 2011;33(4):511-26. [PMID:21392998] http://dx.doi.org/10.1016/j.gaitpost.2011.02.003

10. McNealy LL, Gard SA. Effect of prosthetic ankle units on the gait of persons with bilateral trans-femoral amputations. Prosthet Orthot Int. 2008;32(1):111-26. [PMID:18330810] http://dx.doi.org/10.1080/02699200701847244

11. Darter BJ, Nielsen DH, Yack HJ, Janz KF. Home-based treadmill training to improve gait performance in persons with a chronic transfemoral amputation. Arch Phys Med Rehabil. 2013;94(12):2440-7. [PMID:23954560] http://dx.doi.org/10.1016/j.apmr.2013.08.001

12. Hak L, van Dieën JH, van der Wurff P, Houdijk H. Stepping asymmetry among individuals with unilateral transtibial limb loss might be functional in terms of gait stability. Phys Ther. 2014;94(10):1480-8. [PMID:24903115] http://dx.doi.org/10.2522/ptj.20130431

13. Harbourne RT, Stergiou N. Movement variability and the use of nonlinear tools: Principles to guide physical therapist practice. Phys Ther. 2009;89(3):267-82.

[PMID:19168711] http://dx.doi.org/10.2522/ptj.20080130

14. Gailey R, Allen K, Castles J, Kucharik J, Roeder M. Review of secondary physical conditions associated with lower-limb amputation and long-term prosthesis use. J Rehabil Res Dev. 2008;45(1):15-29. [PMID:18566923] http://dx.doi.org/10.1682/JRRD.2006.11.0147

15. Taylor SM, Kalbaugh CA, Blackhurst DW, Hamontree SE, Cull DL, Messich HS, Robertson RT, Langan EM 3rd, York JW, Carsten CG 3rd, Snyder BA, Jackson MR, Youkey JR. Preoperative clinical factors predict postoperative functional outcomes after major lower limb amputation: An analysis of 553 consecutive patients. J Vasc Surg. 2005;42(2):227-35. [PMID:16102618] http://dx.doi.org/10.1016/j.jvs.2005.04.015

16. McWhinnie DL, Gordon AC, Collin J, Gray DW, Morrison JD. Rehabilitation outcome 5 years after 100 lower-limb 
amputations. Br J Surg. 1994;81(11):1596-9.

[PMID:7827880]

http://dx.doi.org/10.1002/bjs.1800811110

17. Pernot HF, Winnubst GM, Cluitmans JJ, De Witte LP. Amputees in Limburg: Incidence, morbidity and mortality, prosthetic supply, care utilisation and functional level after one year. Prosthet Orthot Int. 2000;24(2):90-6.

[PMID:11061195]

http://dx.doi.org/10.1080/03093640008726531

18. Parker K, Hanada E, Adderson J. Gait variability and regularity of people with transtibial amputations. Gait Posture. 2013;37(2):269-73. [PMID:22939409]

http://dx.doi.org/10.1016/j.gaitpost.2012.07.029

19. Mayfield JA, Reiber GE, Maynard C, Czerniecki JM, Caps MT, Sangeorzan BJ. Trends in lower limb amputation in the Veterans Health Administration, 1989-1998. J Rehabil Res Dev. 2000;37(1):23-30. [PMID:10847569]

20. Butland RJ, Pang J, Gross ER, Woodcock AA, Geddes DM. Two-, six-, and 12-minute walking tests in respiratory disease. Br Med J (Clin Res Ed). 1982;284(6329):1607-8. [PMID:6805625] http://dx.doi.org/10.1136/bmj.284.6329.1607

21. Pin TW. Psychometric properties of 2-minute walk test: A systematic review. Arch Phys Med Rehabil. 2014;95(9): 1759-75. [PMID:24814460] http://dx.doi.org/10.1016/j.apmr.2014.03.034

22. Reuben DB, Magasi S, McCreath HE, Bohannon RW, Wang YC, Bubela DJ, Rymer WZ, Beaumont J, Rine RM, Lai JS, Gershon RC. Motor assessment using the NIH Toolbox. Neurology. 2013;80(11 Suppl 3):S65-S75.

[PMID:23479547] http://dx.doi.org/10.1212/WNL.0b013e3182872e01

23. Pruziner AL, Werner KM, Copple TJ, Hendershot BD, Wolf EJ. Does intact limb loading differ in Servicemembers with traumatic lower limb loss? Clin Orthop Relat Res. 2014;472(10):3068-75. [PMID:24832826] http://dx.doi.org/10.1007/s11999-014-3663-1

24. Fritz S, Lusardi M. White paper: "Walking speed: The sixth vital sign”. J Geriatr Phys Ther. 2009;32(2):46-9.

[PMID:20039582] http://dx.doi.org/10.1519/00139143-200932020-00002

25. Purser JL, Weinberger M, Cohen HJ, Pieper CF, Morey MC, Li T, Williams GR, Lapuerta P. Walking speed predicts health status and hospital costs for frail elderly male Veterans. J Rehabil Res Dev. 2005;42(4):535-46. [PMID:16320148] http://dx.doi.org/10.1682/JRRD.2004.07.0087

26. Stokic DS, Horn TS, Ramshur JM, Chow JW. Agreement between temporospatial gait parameters of an electronic walkway and a motion capture system in healthy and chronic stroke populations. Am J Phys Med Rehabil. 2009;
88(6):437-44. [PMID:19454852]

http://dx.doi.org/10.1097/PHM.0b013e3181a5b1ec

27. Bilney B, Morris M, Webster K. Concurrent related validity of the GAITRite walkway system for quantification of the spatial and temporal parameters of gait. Gait Posture. 2003;17(1):68-74. [PMID:12535728] http://dx.doi.org/10.1016/S0966-6362(02)00053-X

28. Groll DL, To T, Bombardier C, Wright JG. The development of a comorbidity index with physical function as the outcome. J Clin Epidemiol. 2005;58(6):595-602.

[PMID:15878473]

http://dx.doi.org/10.1016/j.jclinepi.2004.10.018

29. Fortin M, Hudon C, Dubois MF, Almirall J, Lapointe L, Soubhi $\mathrm{H}$. Comparative assessment of three different indices of multimorbidity for studies on health-related quality of life. Health Qual Life Outcomes. 2005;3:74.

[PMID:16305743]

http://dx.doi.org/10.1186/1477-7525-3-74

30. Bohannon RW, Wang Y-C, Gershon RC. Two-minute walk test performance by adults 18 to 85 years: Normative values, reliability, and responsiveness. Arch Phys Med Rehabil. 2015;96(3):472-7. [PMID:25450135]

http://dx.doi.org/10.1016/j.apmr.2014.10.006

31. Torburn L, Powers CM, Guiterrez R, Perry J. Energy expenditure during ambulation in dysvascular and traumatic below-knee amputees: A comparison of five prosthetic feet. J Rehabil Res Dev. 1995;32(2):111-9.

[PMID:7562650]

32. Cumming JC, Barr S, Howe TE. Prosthetic rehabilitation for older dysvascular people following a unilateral transfemoral amputation. Cochrane Database Syst Rev. 2006; (4):CD005260. [PMID:17054250]

33. Barth DG, Schumacher L, Thomas SS. Gait analysis and energy cost of below-knee amputees wearing six different prosthetic feet. J Prosthet Orthot. 1992;4(2):63-75. http://dx.doi.org/10.1097/00008526-199212000-00001

34. Pagliarulo MA, Waters R, Hislop HJ. Energy cost of walking of below-knee amputees having no vascular disease. Phys Ther. 1979;59(5):538-43. [PMID:441113]

35. Geurts AC, Mulder TW, Nienhuis B, Rijken RA. Dual-task assessment of reorganization of postural control in persons with lower limb amputation. Arch Phys Med Rehabil. 1991;72(13):1059-64. [PMID:1741657]

36. Lin SJ, Winston KD, Mitchell J, Girlinghouse J, Crochet K. Physical activity, functional capacity, and step variability during walking in people with lower-limb amputation. Gait Posture. 2014;40(1):140-4. [PMID:24731451] http://dx.doi.org/10.1016/j.gaitpost.2014.03.012

37. Johnson VJ, Kondziela S, Gottschalk F. Pre and postamputation mobility of trans-tibial amputees: Correlation to medical problems, age and mortality. Prosthet Orthot Int. 1995;19(3):159-64. [PMID:8927527] 
38. Bussmann JB, Grootscholten EA, Stam HJ. Daily physical activity and heart rate response in people with a unilateral transtibial amputation for vascular disease. Arch Phys Med Rehabil. 2004;85(2):240-4. [PMID:14966708] http://dx.doi.org/10.1016/S0003-9993(03)00485-4

39. Bussmann JB, Schrauwen HJ, Stam HJ. Daily physical activity and heart rate response in people with a unilateral traumatic transtibial amputation. Arch Phys Med Rehabil. 2008;89(3):430-4. [PMID:18295619] http://dx.doi.org/10.1016/j.apmr.2007.11.012

40. Deathe AB, Miller WC. The L test of functional mobility: Measurement properties of a modified version of the timed "up \& go" test designed for people with lower-limb amputations. Phys Ther. 2005;85(7):626-35. [PMID:15982169]
Submitted for publication March 4, 2015. Accepted in revised form December 15, 2015.

This article and any supplementary material should be cited as follows:

Loyd BJ, Fields TT, Stephenson RO, Stevens-Lapsley JE, Christiansen CL. Explaining modified 2-min walk test outcomes in male Veterans with traumatic or nontraumatic lower-limb amputation. J Rehabil Res Dev. 2016; 53(6):1035-44.

http://dx.doi.org/10.1682/JRRD.2015.03.0038

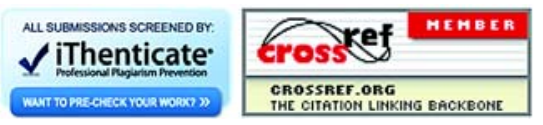

